\title{
Effects of Respiratory Muscle Training on the Respiratory Function, Balance, and Activities of Daily Living in Patients with Stroke
}

\author{
Tae-Woo Kang' ${ }^{1}$ Beom-Ryong Kim² \\ 'Department of Physical Therapy, Wonkwang University Hospital, Iksan; ${ }^{2}$ Department of Physical Therapy, Design Hospital, Jeonju, Korea
}

Purpose: This study evaluated the effects of respiratory muscle training on respiratory function, balance, and activities of daily living (ADL) in patients with stroke.

Methods: The study included 21 patients with stroke, divided into the experimental group and control group. Both groups underwent traditional physical therapy once a day for 30 minutes, five times weekly for 6 weeks. The experimental group underwent additional respiratory muscle training once a day, five times a week during the study period. Maximal inspiratory pressure (MIP), maximal expiratory pressure (MEP), Berg balance scale (BBS), and Korean-modified Barthel index (K-MBI) were measured before and after the study period. For statistical analysis, paired t-test was used to compare the difference between the pre and post values. Independent t-test was used compare the differences between groups.

Results: Both groups had significantly improved MIP, MEP, BBS, and K-MBI scores after the study period. The experimental group had significantly improved MIP, MEP, BBS, and K-MBI scores.

Conclusion: These results suggest that respiratory muscle training improves respiratory function, balance, and ADL in patients with stroke.

Keywords: Activities of daily living, Balance, Respiratory function, Respiratory muscle training, Stroke

\section{서 론}

뇌졸중 이후 환자들은 운동과 감각기능의 장애로 신체적 활동에 제 약을 받게 되고, 주로 의식수준의 변화, 감각과 운동기능 상실, 인지 와 지각능력의 손상이 나타나며, 운동기능의 상실로 인해 근력의 저 하가 발생하게 된다. ${ }^{1,2}$ 근력의 저하는 뇌졸중 환자의 팔다리 움직임 을 저하시킬 뿐만 아니라 호흡기능의 약화를 초래한다. 일반적으로 뇌졸중 이후 대부분의 환자들은 호흡문제가 발생하지만, 다른 문제 에 비해서 상대적으로 관심을 덜 갖게 되는데, 이는 호흡질환에서 나 타나는 것과 같은 명백한 증상이 나타나지 않기 때문이다. ${ }^{3}$ 뇌졸중 이후 부분적으로나 전체적으로 마비측의 호흡근의 약화가 있고, 가 슴우리(thoracic cage) 확장제한 및 몸통의 잘못된 자세조절 등의 이유 로 호흡기능에 문제가 발생한다. ${ }^{3}$

호흡은 호흡관련 근육들과 신경학적 조절로 이루어지며 폐가 둘 러싸고 있는 공기와 혈액 사이의 환기 및 교환역할을 한다. ${ }^{4}$ 호흡 근
육들은 흡기근과 호기근으로 나누어지는데, 흡기에 관여하는 주요 근육은 가로막, 바깥갈비사이근으로 평상시 호흡(tidal breathing)과 연관이 있다. 흡기보조근은 목빗근, 목갈비근, 등세모근, 큰가슴근, 작 은가슴근, 앞톱니근, 넓은등근이 있으며 심흡기 때 활동하는 근육이 다. 호기에 관여하는 주요근육은 평상시 호기가 수동적이기 때문에 관여하지 않고, 부수적 근육은 배곧은근, 배가로근, 배바깥빗근, 배 속빗근, 속갈비사이근이 있으며 심호기에서 활동한다. 뇌졸중 환자 의 호흡은 일반적으로 흡기근과 호기근의 최대수축과 지구력이 감 소하며 가슴우리의 운동학적 움직임도 줄어든다. ${ }^{6,7}$ 뇌졸중 환자의 최대흡기량과 최대호기량은 나이가 비슷한 정상성인에 비해 현저하 게 낮으며, 이는 뇌졸중 환자의 호흡근력이 상당히 약해짐을 의미한 다. Teizeira-Salmela 등 ${ }^{8}$ 은 건강한 대상자와 비교하여 뇌졸중 환자들 은 호흡 동안 가슴우리의 움직임이 현저히 낮으며 최대흡기압과 최 대호기압이 상당히 낮다고 보고하였다. 이러한 이유로, 뇌졸중 환자 는 장시간 활동을 요하는 유산소 운동 시 쉽게 피곤함을 느끼고 일상
Received Mar 14, 2018 Revised Apr 7, 2018

Accepted Apr 16, 2018

Corresponding author Beom-Ryong Kim

E-mail kimbr21@hanmail.net
Copylight (C)2018 The Korea Society of Physical Therapy

This is an Open Access article distribute under the terms of the Creative Commons Attribution Non-commercial License (Http:// creativecommons.org/license/by-nc/4.o.) which permits unrestricted non-commercial use, distribution, and reproduction in any medium, provided the original work is properly cited. 
생활수행능력의 저하를 보인다. ${ }^{9}$

호흡훈련은 균형능력과 일상생활수행능력에 영향을 미친다는 연 구들이 보고되고 있다. $\mathrm{Kim}$ 등 10 은 뇌졸중 환자를 대상으로 흡기근 과 복부심부근을 병행한 호흡근 강화운동을 실시하여 일상생활수 행능력의 향상을 보여 호흡훈련과 일상생활수행능력의 연관성을 보 고하였고, Kang 등'은 뇌졸중 환자를 대상으로 노력성 호기근인 배 가로근 강화운동을 통해서 균형능력의 향상을 보고하였으며, Kim과 $\operatorname{Park}^{12}$ 은 뇌졸중 환자를 대상으로 고빈도가슴벽진동과 트레드밀 훈 련을 실시하여 일상생활을 수행할 수 있는 기능의 향상을 보고하였 다. 이와 같이 뇌졸중 환자를 대상으로 호흡근육이나 호흡능력과 관 련된 중재들이 적용되고 있으며, 호흡훈련이 균형능력과 일상생활수 행능력의 관련성을 볼수 있다.

호흡을 위한 재활운동은 일반적으로, 흡기근을 강화시키는 방법이 있는데, 이는 대상자가 흡기 시 최대흡기압력의 저항이나 견딜 수 있 는 정도의 저항을 유도할 수 있는 호흡훈련을 적용한다. 호흡훈련을 통하여 근육이 운동에 적응하면서 구조와 기능이 변화된다. 또한, 입 술 오므리기 호흡(puresed-lip breathing)운동, 가로막 호흡운동 등이 임상에서 호흡재활을 위하여 적용되고 있다. ${ }^{13}$ 이렇게 흡기근을 강화 시키는 다양한 운동법과 입술 오므리기 호흡운동, 가로막 호흡운동 이 임상에서 적용되고 있음에도 불구하고 뇌졸중 환자에게는 유산 소 운동과 근력 운동을 통해 호흡능력을 향상시키는 연구만 진행되 고 있고 직접적으로 호흡훈련을 적용하는 연구는 부족한 실정이다.

따라서 본 연구는 뇌졸중 환자를 대상으로 호흡훈련을 적용하여 뇌졸중 환자의 호흡기능과 균형 및 일상생활수행능력에 어떠한 영 향을 미치는지 알아보고자 하였다.

\section{연구방법}

\section{1. 연구 대상자}

본 연구는 뇌졸중으로 진단을 받고 6 개월 이상 경과된 뇌졸중 환자 들을 대상으로 본 연구의 취지를 이해하고 참여하겠다고 동의한 21 명의 환자들을 대상으로 하였다. 연구 대상자 선정 기준은 다음과 같 다. 첫째, 뇌졸중 이외의 특별한 폐 관련 질환 병력이 없는 자, 둘째, 선 천적으로 가슴우리와갈비뼈의 정형외과적 질환이 없는 자, 셋째, 폐 기 능의 향상을 위해 특별한 치료를 받지 않았던 자, 넷째, 한국판간이정신 상태판별검사(mini-mental state examination-Korean version: MMES-K) 점수가24점 이상인 자를 대상으로 하였다.

\section{2. 연구과정}

뇌졸중 발병 후 6 개월이 지난 만성 뇌졸중 환자 21 명을 대상으로 무 작위 배치방법으로 일반적인 물리치료와 호흡훈련을 실시하는 실험
군 10 명과 일반적인 물리치료만을 시행하는 대조군 11 명으로 나누었 다. 훈련은 주 5 회, 6 주간 실시하였다.

\section{1) 호흡훈련}

흡기성 가로막 호흡훈련은 치료사의 손을 앞 갈비뼈연골 바로 아래 의 배곧은근에 올려놓은 다음 환자에게 느리고 깊게 코로 숨을 들이 마시도록 가로막 호흡을 유도한다. 이때 치료사는 앞 갈비뼈연골 바 로 아래의 배곧은근이 상승될 때 적절한 저항을 가하며 환자의 심흡 기를 유도한다. 환자는 심흡기를 하는 동안 어깨를 이완시켜 유지하 게 하고 위 가슴은 움직이지 않게 하며 배의 상승만 허용한다. 흡기성 가로막 호흡이 끝나면 곧바로 호기성 입술 오므리기 호흡운동을 실 시한다. 환자는 조절된 심흡기를 이용하여 입술을 오므리고 일정한 시간 동안 공기를 밖으로 내쉬도록 한다. ${ }^{13}$ 연구자는 흡기성 가로막 운동과 호기성 입술 오므리기 운동을 환자에게 충분히 이해할 수 있 도록 설명과 시범을 보여준 다음 실시하였다. 호흡훈련을 매회 시작 하기 전에 준비운동으로 수차례씩 심호흡과 몸통의 회전운동을 실 시하여 환자의 신체의 긴장도를 완화시키고 본 운동을 실시하였다. 호흡훈련을 실시하는 도중 환자가 피로감 또는 어지러움을 느끼면 잠시 쉬었다가 다시 진행하였으며 증상이 심한 경우에는 호흡훈련을 중단하였다. 각각의 호흡훈련은 최대 5 세트로 하였고, 주 차별 대상 자가 1주 7회, 2-3주 10회, 4-5주 15회, 6주 20회로 주기적으로 횟수를 증가시켜서 실시하였다. 세트 간에는 30 초 정도의 휴식을 취하게 하 고, 다음 운동으로 넘어가게 하였으며, 훈련시간은 30 분을 넘지 않도 록하였다.

\section{2) 일반적인 물리치료}

일반적인 물리치료는 관절가동범위 운동으로서, 수동운동, 능동보 조운동, 능동운동, 저항운동, 신장운동을 실시하였다. 균형과 보행을 위한 훈련으로는 기능적 접근법인 반사를 억제하고 촉진전략을 사 용하는 신경발달치료, 고유수용성신경근촉진법을 사용하였다.

\section{3) 측정방법 \\ (1) 최대흡기압과 최대호기압 측정}

폐활량 검사의 측정도구인 Pony Fx (Cosmed Srl, ITALY)를 이용하여 뇌 졸중 환자의 특성상 환자의 안전을 고려하여 앉은 자세에서 실시하였 다. 검사자세는 허리와 어깨를 곧게 펴고, 다리는 어깨 넓이로 벌려 지 면과 수직으로 놓이게 하였다. 코 집게를 이용하여 코를 막고 한 손으 로는 측정도구를 잡아 마우스를 물게 하였다. 평가 전에 대상자들이 검사방법을 숙지할 수 있도록 반복적으로 교육을 실시하였으며, 최대 흡기압력(maximal inspiratory pressure, $\mathrm{MIP})$ 을 먼저 측정한 후, 충분한 휴식을 취한 후에 최대호기압력(maximal expiratory pressure, MEP)을 
측정하였다. 세번의 측정을 통하여 가장 높은 수치를 기록하였다.

\section{(2) 버그균형척도(Berg's balance scale, BBS)}

이 검사는 노인들의 수행을 직접 관찰하여 균형능력과 낙상 위험을 양적으로 평가하는 도구이다. ${ }^{14}$ 앉기, 서기, 자세변화 등을 통해 균형 을 유지하는 능력을 평가하며, 약 20 분 정도의 시간이 소요된다. 총 14 개의 항목으로 구성되며 과제를 수행할 수 없는 경우 최소 0 점에서 독립적으로 완벽히 수행할 경우 최고 4점으로 총점은 56점이다. 0-20 점은 심각한 균형 장애를 가지고 있다고 판단하고, 21-40점은 경도의 균형 장애, 41-56점은 좋은 균형능력을 가지고 있다고 본다. 이 평가도 구는 높은 타당도와 측정자 내 신뢰도 $(\mathrm{ICC}=0.97)$, 측정자 간 신뢰도 (ICC=0.95-98), 평가-재평가 신뢰도 $(\mathrm{ICC}=0.98)$ 를 갖는다. ${ }^{15}$

\section{(3) 한글판 수정바델지수(Korean-modified Barthel index, K-MBI)}

일상생활수행능력을 평가하기 위한 도구로 직접적인 관찰을 통하여 평가가 이루어진다. 평가항목은 총 10 가지 항목으로 구성되며, 10 개 의 항목은 개인위생, 목욕하기, 식사하기, 용변처리, 계단 오르기, 옷 입기, 대변조절, 소변조절, 보행 또는 휠체어, 의자/침대 이동으로 구성

Table 1. General characteristics of subjects

\begin{tabular}{lccc}
\hline \multirow{2}{*}{ Group } & Experimental & Control & \\
\cline { 2 - 3 } & Group $(\mathrm{n}=10)$ & Group $(\mathrm{n}=11)$ & \\
\hline Gender (Male/Female) & $(7 / 3)$ & $(8 / 3)$ & 0.90 \\
Age (Year) & $63.20 \pm 3.39$ & $62.36 \pm 4.38$ & 0.63 \\
Height $(\mathrm{cm})$ & $163.80 \pm 2.97$ & $163.09 \pm 5.24$ & 0.71 \\
Weight $(\mathrm{kg})$ & $61.90 \pm 5.21$ & $60.72 \pm 5.81$ & 0.63 \\
Body mass index (kg/m²) & $23.03 \pm 1.92$ & $22.82 \pm 1.77$ & 0.80 \\
Side of stroke lesion (Left/Right) & $(8 / 2)$ & $(8 / 3)$ & 0.70 \\
Stroke Type & $(6 / 4)$ & $(7 / 4)$ & 0.86 \\
(Hemorrhage/lnfarction) & & & \\
Time since stroke (month) & $9.30 \pm 0.48$ & $8.90 \pm 1.44$ & 0.43 \\
MMES-K & $25.70 \pm 2.05$ & $25.63 \pm 2.37$ & 0.95 \\
\hline
\end{tabular}

Table 2. The comparison of variable on pre and post in group

\begin{tabular}{llcccc}
\hline & Group & Pre & Post & $\mathrm{t}$ & $\mathrm{p}$ \\
\hline MIP & Experimental & $24.90 \pm 2.92$ & $30.80 \pm 2.62$ & -8.00 & $0.00^{*}$ \\
& Control & $23.45 \pm 2.07$ & $27.55 \pm 0.93$ & -6.01 & $0.00^{*}$ \\
MEP & Experimental & $31.80 \pm 4.37$ & $35.40 \pm 3.84$ & -10.00 & $0.00^{*}$ \\
& Control & $30.36 \pm 4.00$ & $33.09 \pm 4.55$ & -7.78 & $0.00^{*}$ \\
BBS & Experimental & $35.40 \pm 3.84$ & $45.00 \pm 2.05$ & -9.00 & $0.00^{*}$ \\
& Control & $33.09 \pm 4.55$ & $38.36 \pm 4.46$ & -12.97 & $0.00^{*}$ \\
\multirow{3}{*}{ K-MBI } & Experimental & $60.60 \pm 3.57$ & $73.30 \pm 3.16$ & -9.90 & $0.00^{*}$ \\
& Control & $58.82 \pm 5.12$ & $66.64 \pm 3.59$ & -6.33 & $0.00^{*}$ \\
\hline
\end{tabular}

Values are presented as mean \pm standard deviation.

MIP: maximal inspiratory pressure, MEP: maximal expiratory pressure, BBS Berg's balance scale, K-MBI: Korean-modified Barthel index. ${ }^{*} p<0.01$.
되어 있으며 총점은 100 점이다. $0-24$ 점은 완전 의존성, $25-49$ 점은 최 대 의존성, 50-74점은 부분 의존성, 75-90점은 약간 의존성, 91-99점은 최소 의존성, 100 점은 완전한 독립적인 일상생활수행을 의미한다. ${ }^{16}$ 이 평가도구는 높은 검사-재검사 신뢰도 $(r=0.89)$ 와 검사자 간 신뢰도 $(\mathrm{r}=0.95)$ 를 갖는다. ${ }^{17}$

\section{3. 자료 처리}

본 연구의 대상자의 일반적인 특성은 기술적인 통계를 통해서 기술 하였다. 연구의 결과는 SPSS version 18.0 for Window를 사용하였다. 실 험군과 대조군의 치료 중재 전 동질성 검사를 위해 독립표본 $\mathrm{t}$-검정 을 실시하였다. 각 실험군과 대조군 내에 중재 전과 후의 유의성 검증 은 대응표본 $\mathrm{t}$-검정을 하였고, 각 군 간 유의성 검증은 독립표본 $\mathrm{t}$-검 정을 실시하였다. 통계학적 유의수준 $\mathrm{p}=0.05$ 로 설정하였다.

\section{결 과}

\section{1. 연구 대상자의 일반적 특성}

본 연구에 참여한 대상자들의 일반적 특성은 Table 1과 같으며 실험 전 두 집단의 동질성을 분석한 결과 연령, 신장, 체중, 체질량지수, 발 병기간, 한국판간이정신상태판별검사 등의 대상자의 일반적 특성은 유의한차이가 없었다.

\section{2. 호흡기능에 대한 효과}

실험군과 대조군의 실험 전, 후 최대흡기압(MIP)에서 실험 전보다 실 험 후에 유의하게 향상되었다 $(\mathrm{p}<0.05)$. 실험 후 실험군과 대조군의 최 대흡기압(MIP)에서 유의한 차이가 있었다 $(\mathrm{p}<0.05)$. 실험군과 대조군 의 실험 전, 후 최대호기압(MEP)에서 실험 전보다 실험 후에 유의하 게 향상되었다 $(\mathrm{p}<0.05)$. 실험 후 실험군과 대조군의 최대호기압 (MEP)에서 유의한 차이가 있었다 $(\mathrm{p}<0.05)($ Table 2, 3).

\section{3. 균형능력에 대한 효과}

실험군과 대조군의 실험 전, 후 균형능력(BBS)에서 실험 전보다 실험

Table 3. The comparison of changes in variables between post-test in both group

\begin{tabular}{lcccc}
\hline & Experimental & Control & $\mathrm{t}$ & $\mathrm{p}$ \\
\hline MIP & $30.80 \pm 2.62$ & $27.55 \pm 0.93$ & 3.87 & $0.00^{*}$ \\
MEP & $35.40 \pm 3.84$ & $33.09 \pm 4.55$ & 4.06 & $0.00^{*}$ \\
BBS & $45.00 \pm 2.05$ & $38.36 \pm 4.46$ & 4.31 & $0.00^{*}$ \\
K-MBI & $73.30 \pm 3.16$ & $66.64 \pm 3.59$ & 4.50 & $0.00^{*}$ \\
\hline
\end{tabular}

Values are presented as mean \pm standard deviation

MIP: maximal inspiratory pressure, MEP: maximal expiratory pressure, BBS: Berg's balance scale, K-MBI: Korean-modified Barthel index. ${ }^{*} \mathrm{p}<0.01$. 
후에 유의하게 향상되었다 $(\mathrm{p}<0.05)$. 실험 후 실험군과 대조군의 균형 능력(BBS)에서 유의한 차이가 있었다( $<<0.05)(T a b l e s 2,3)$.

\section{4. 일상생활수행능력에 대한 효과}

실험군과 대조군의 실험 전, 후 일상생활수행능력(K-MBI)에서 실험 전보다 실험 후에 유의하게 향상되었다 $(\mathrm{p}<0.05)$. 실험 후 실험군과 대 조군의 일상생활수행능력(K-MBI)에서 유의한 차이가 있었다 $(\mathrm{p}<$ 0.05)(Tables 2,3).

\section{고 찰}

뇌졸중 이후 환자들은 마비측의 호흡근의 약화와 가슴우리의 적절 한 확장의 제한을 보여 호흡기능에 문제가 발생한다. 호흡훈련은 호 흡근이 약화된 환자에게 호흡근의 기능을 향상시킬 뿐만 아니라 운 동능력을 향상시키는 효과를 가지고 있다. ${ }^{3}$ 이에 본 연구는 뇌졸중 환자에게 호흡훈련을 적용하여 호흡기능과 균형 및 일상생활수행능 력에 미치는 영향을 알아보고자 하였다. 연구 결과 호흡훈련을 실시 한 실험군에서 최대흡기압, 최대호기압, 버그균형척도, 한글판 수정 바델지수에서 유의한 차이가 있었다.

본 연구에서 최대흡기압과 최대호기압이 두 그룹에서 모두 중재 전후에 유의하게 증가하였고, 중재 후의 결과에서 실험군이 대조군 에 비해 유의하게 최대흡기압과 호기압이 증가하였다. 본 연구의 결 과는 뇌졸중 환자를 대상으로 호흡근 훈련을 시킨 다른 연구결과와 일치한다. Messaggi-Sartor 등은 109명의 뇌졸중 환자를 호흡운동을 실시한 56명과 유사운동을 실시한 53명으로 나누어 3 주간 중재를 적 용한 결과 호흡운동을 실시한 그룹에서 최대호기압이 증가하였다고 보고하였다. 뇌졸중 환자는 일반적으로 뇌영역 중 운동영역의 손상 으로 호흡근의 근력이 약화되어 같은 연령대의 건강한 사람에 비해 기침능력이 3 분의 1 로 감소한다.1819 특히, 호흡근 중에서도 호기근들 의 약화는 뇌졸중 환자에게 흡인성 폐렴을 유발시키는 중요한 원인 중에 하나이기 때문에 중요하다..$^{20}$ 또한, 최대흡기압과 최대호기압의 증가로 인한 호흡능력의 향상은 재활과정에서 강도 높은 훈련에도 빠른 회복이 가능해지고, 더 기능적인 훈련의 수행이 가능해져 결과 적으로 사회로의 복귀가 당겨질 것으로 사료된다.

본 연구에서 뇌졸중 환자의 균형능력을 평가하기 위하여 버그균 형척도를 실시하였다. 버그균형척도 점수를 중재 전후 비교해본 결과 실험군과 대조군에서 모두 통계적으로 유의한 증가가 있었다. Kim 등 11 은 뇌졸중 환자를 대상으로 가로막과 바깥갈비사이근의 근 활성도 가 유의하게 증가하였다고 보고하였다. $\mathrm{Kim}^{22}$ 은 뇌졸중 환자를 대상 으로 호기근육 훈련을 6 주 동안 주 5 회 실시하여 대조군과 비교하여 몸통조절능력의 유의한 향상이 있음을 보고하였다. 이러한 연구 결
과는 호흡근운동을 통하여 호흡근의 근 활성도가 증가하고 호흡근 들은 몸통의 자세 조절 능력과 밀접한 관계가 있기 때문에 호흡근의 향상은 몸통조절능력의 향상과 관련이 있을 수 있다. ${ }^{23}$ 몸통의 조절 능력은 신체가 바르게 선 자세를 유지하도록 하며 체중 이동을 조절 하여 균형을 유지하는 데 매우 중요한 역할을 한다. ${ }^{23}$ 비록, 본 연구에 서는 평가하지 않았으나 사전연구들의 결과를 통하여 호흡운동 후 호흡근의 근력 증가가 몸통의 자세 조절에 영향을 미쳐 균형능력의 유의한 향상을 가져온 것으로 사료된다. 버그균형척도의 항목은 사 회참여와 활동과정에서 무의식적으로 이루어지는 동작으로 생각되 며, 본 연구의 결과에서 보여주듯 호흡근의 강화는 균형능력의 향상 으로 볼 때 뇌졸중 환자의 재활과정에서 호흡근강화를 위한 중재가 필요할 것으로 사료된다.

한국판 수정바델지수 점수의 중재 전후 비교해본 결과 실험군과 대조군 모두 유의한 차이가 있었고, 중재 후 실험군에서 대조군에 비 해 유의한 향상이 있었다. 몸통조절능력은 호흡하기, 말하기, 보행하 기, 균형 잡기, 상지의 기능적 사용 등과 같은 일상생활수행능력과 깊 은 관계를 가진다고 보고되며, 본 연구에서 호흡근훈련을 통하여 균 형능력의 향상을 보인 것으로 보아 몸통조절능력이 향상된 것으로 사료된다. ${ }^{24}$ 호흡근운동이 일상생활수행능력을 증진시키는 이유는 운동저항력을 향상시키는 효과가 있기 때문이다. ${ }^{25}$ 운동저항력은 흡 기근이 공기를 폐 안쪽으로 받아들이는 능력이라 할 수 있는데, 운동 저항력이 증가된다는 의미는 분당 환기량을 증가시키고, 운동의 피 로를 줄여주는 것이다. ${ }^{26}$ Stubeyaz 등 3 은 45 명의 뇌졸중 환자를 대상으 로 15명씩 나누어 흡기근 훈련군, 가로막 호흡과 입술 오므리기 훈련 군, 대조군으로 나누어 6주간 중재를 적용한 결과 흡기근 훈련군에 서 삶의 질이 유의하게 향상되었다. 호흡근운동은 줄어든 폐용적을 늘려주며 운동저항력을 증진시키기 때문에 궁극적으로 뇌졸중 환자 의 일상생활수행능력을 향상시키는 데 도움이 된다. ${ }^{27} \mathrm{Park}$ 과 $\mathrm{Hong}^{28}$ 은 호흡능력이 한국판 수정바델지수 중 개인위생, 목욕하기, 식사하 기, 용변처리, 옷 입기 항목에 관련성을 보고하였으며, 호흡훈련이 뇌 졸중 환자의 한국판 수정바델지수를 향상시키는 중재방법이 될 수 있다고 하였다. 이와 같이 선행연구들을 비춰볼 때 뇌졸중환자의 일 상생활동작수행의 개선을 위해서는 본 연구의 호흡훈련의 필요성을 시사한다.

본 연구에서 최대흡기압, 최대호기압, 버그균형척도 및 한국판 수 정바델지수는 중재 후의 결과에서 실험군이 대조군에 비해 유의하 게 증가하였다. 이러한 결과는 실험군에게만 개개인에 따라 불특정 한 시간의 호흡훈련을 추가하였기 때문이다. 이는 본 연구 결과 각 실 험군과 대조군에서 6 주 중재 전후 결과비교에서 두 군 모두 유의한 결과에서 알 수 있듯이, 실험군에서 일반적인 물리치료 후 호흡훈련 이 아닌 다른 중재방법을 적용했을 때에도 이와 유사한 결과를 얻을 
것으로 생각된다. 따라서 대조군에게도 실험군에서 호흡훈련을 한 시간만큼 다른 중재를 추가하였는데, 호흡훈련을 시행한 실험군에 서 유의한 결과를 보여주었다면 더 의미 있는 결과가 되었을 것이라 사료된다. 또한, 호흡훈련 시간을 환자 개개인의 특성에 따라 피로감 또는 어지러움을 느끼면 잠시 쉬었다가 다시 진행하였으며 증상이 심한 경우에는 호흡훈련을 중단했다는 애매모호한 시간의 제시가 아니라 기존 선행연구를 바탕으로 시간을 설정하여 호흡훈련을 실 시한 후에 결과 값을 측정하였다면 더욱 신뢰할 수 있는 결과를 얻었 을 것으로 사료된다.

본 연구의 결과를 해석하는 데 있어 몇 가지 제한점을 가지고 있다. 첫째, 연구의 효과가 지속되었는지 추적 관찰이 이루어지지 않았다. 둘째, 대상자의 수가 상대적으로 적어 이를 일반화시키는 데 한계가 있었다. 셋째, 호흡훈련을 통하여 몸통조절능력이 향상되었다는 것 을 평가할 수 있는 객관적인 평가가 이루어지지 않았다. 그러므로, 향 후에는 객관화된 평가도구를 이용한 몸통조절과 보행에 대한 평가 가 이루어지는 추후 연구가 필요할 것으로 사료된다.

\section{참고문헌}

1. Kolb B, Gibb R. Brain plasticity and recovery from early cortical injury. Dev Psychobiol. 2007;49(2):107-18.

2. O'Sullivan SB, Schmitz TJ. Physical rehabilitation: Assessment and treatment. 4th ed. Philadelphia, FA Davis, 2001:520-58.

3. Sutbeyaz ST, Koseoglu F, Inan L et al. Respiratory muscle training improves cardiopulmonary function and exercise tolerance in subjects with subacute stroke: A randomized controlled trial. Clin Rehabil. 2010; 24(3):240-50.

4. Pryor JA, Prasad SA. Physiotherapy for respiratory and cardiac problems-adults and paediatrics. 3rd ed. London, Churchill Livingstone, 2002.

5. Cameron MH, Monroe LG. Physical rehabilitation: Evidence-based examination, evaluation, and intervention. Philadelphia, Saunders, 2007.

6. Lima IN, Fregonezi GA, Melo R et al. Acute effects of volume-oriented incentive spirometry on chest wall volumes in patients after a stroke. Respir Care. 2014;59(7):1101-7.

7. Messaggi-Sartor M, Guillen-Sola A, Depolo M et al. Inspiratory and expiratory muscle training in subacute stoke: A randomized clinical trial. Neurology. 2015;85(7):564-72.

8. Teixeira-Salmela LF, Parreira VF, Britto RR et al. Respiratory pressures and thoracoabdominal motion in community-dwelling chronic stroke survivors. Arch Phys Med Rehabil. 2005;86(10):1974-8.

9. Reid WD, Samrai B. Respiratory muscle training for patients with chronic obstructive pulmonary disease. Phys Ther. 1995;75(11):996-1005.

10. Kim BR, Kang JI, Kim YN et al. Effects of respiratory muscle strengthening exercise on respiratory function and activities of daily living in stroke patients. J Kor Phys Ther. 2017:29(1):1-6.

11. Kang JI, Kim BR, Park SK et al. Effects of deep abdominal muscle strengthening exercises on pulmonary function and the ability to balance in stroke patients. J Kor Phys Ther. 2015:27(4):258-63.

12. Kim BR, Jin Park J. Effect of the high frequency chest wall oscillation (HFCWO) on pulmonary function and walking ability in stroke patients. J Kor Phys Ther. 2017:29(2):50-4.

13. Jones AY, Dean E, Chow CC. Comparison of the oxygen cost of breathing exercises and spontaneous breathing in patients with stable chronic obstructive pulmonary disease. Phys Ther. 2003;83(5):424-31.

14. Berg KO, Wood-Dauphinee SL, Williams JI et al. Measuring balance in the elderly: Validation of an instrument. Can J Public Health. 1992;83: S7-11.

15. Blum L, Korner-Bitensky N. Usefulness of the Berg balance scale in stroke rehabilitation: A systematic review. Phys Ther. 2008;88(5):559-66.

16. Shah S, Vanclay F, Cooper B. Improving the sensitivity of the Barthel index for stroke rehabilitation. J Clin Epidemiol. 1989;42(8):703-9.

17. Granger CV, Albrecht GL, Hamilton BB. Outcome of comprehensive medical rehabilitation: Measurement by PULSES profile and the Barthel index. Arch Phys Med Rehabil. 1979;60(4):145-54.

18. Harraf F, Ward K, Man W et al. Transcranial magnetic stimulation study of expiratory muscle weakness in acute ischemic stroke. Neurology. 2008;71(24):2000-7.

19. Ward K, Seymour J, Steier J et al. Acute ischaemic hemispheric stroke is associated with impairment of reflex in addition to voluntary cough. Eur Respir J. 2010;36(6):1383-90.

20. Kulnik ST, Rafferty GF, Birring SS et al. A pilot study of respiratory muscle training to improve cough effectiveness and reduce the incidence of pneumonia in acute stroke: Study protocol for a randomized controlled trial. Trails. 2014;15:123.

21. Kim CY, Lee JS, Kim HD et al. Effects of the combination of respiratory muscle training and abdominal drawing-in maneuver on respiratory muscle activity in patients with post-stroke hemiplegia: A pilot randomized controlled trial. Top Stroke Rehabil. 2015;22(4):262-70.

22. Kim MH. The effects of respiratory function, trunk control and functional ADL following respiratory strength training in patients with stroke. Sahmyook University. Dissertation of Doctorate Degree. 2012.

23. Hodges PW, Gandevia SC. Activation of the human diaphragm during a repetitive postural task. J Physiol. 2000;522(1):165-75.

24. Verheyden G, Vereeck L, Truijen S et al. Trunk performance after stroke and the relationship with balance, gait, and functional ability. Clin Rehabil. 2006;20(5):451-8.

25. Sezer N, Ordu NK, Sutbeyaz ST et al. Cardiopulmonary and metabolic responses to maximum exercise and aerobic capacity in hemiplegic patients. Funct Neurol. 2004;19(4):233-8.

26. Gomes-Neto M, Saquetto MB, Silva C et al. Effects of respiratory muscle training on respiratory function, respiratory muscle strength, and exercise tolerance in patients poststroke: A systematic review with metaanalysis. Arch Phys Med Rehabil. 2016;97(11):1994-2001.

27. Haas A, Rusk HA, Pelosof $\mathrm{H}$ et al. Respiratory function in hemiplegic patients. Arch Phys Med Rehabil. 1967;48(4):174-9.

28. Park GA, Hong JR. Correlation between respiratory function and performance of activities of daily living in stroke patients. J Rehabil Res. 2014;18(3):309-21. 